\title{
Associations of Starch Gel Hardness, Granule Size, Waxy Allelic Expression, Thermal Pasting, Milling Quality, and Kernel Texture of 12 Soft Wheat Cultivars
}

\author{
C. S. Gaines, ${ }^{1,2}$ M. Ö. Raeker, ${ }^{3}$ M. Tilley, ${ }^{4}$ P. L. Finney, ${ }^{1}$ J. D. Wilson, ${ }^{4}$ D. B. Bechtel, ${ }^{4}$ R. J. Martin, ${ }^{1}$ \\ P. A. Seib, ${ }^{5}$ G. L. Lookhart, ${ }^{4}$ and T. Donelson ${ }^{1}$
}

ABSTRACT

Cereal Chem. 77(2):163-168

\begin{abstract}
Starches were isolated from 12 soft wheat (Triticum aestivum L.) cultivars and were characterized for waxy $(W x)$ allelic expression, thermal pasting characteristics, and starch granule size. Gels were produced from the thermally degraded starches and were evaluated using large deformation rheological measurements. Data were compared with cultivar kernel texture, milling characteristics, starch chemical analyses, and flour pasting characteristics. Larger flour yields were produced from cultivars that had larger starch granules. Flour yield also was correlated with lower amylose content and greater starch content. Harder starch gels were correlated with higher levels of amylose content and softer kernel texture.
\end{abstract}

The cultivar Fillmore, which had a partial waxy mutation at the B locus, produced the highest peak pasting viscosity and the lowest gel hardness. Softer textured wheats had greater lipid-complexed amylose and starch phosphorus contents and had less total starch content. Among these wheats of the soft market class, softer textured wheats had larger starch granules and harder textured wheats had smaller starch granules. In part, this may explain why soft wheats vary in texture. The smaller granules have larger surface area available for noncovalent bonding with the endosperm protein matrix and they also may pack more efficiently, producing harder endosperm.
Starch is the major constituent of wheat endosperm and thus has a major role in the properties of the flour and products made from the flour. Typically, wheat (Triticum aestivum L.) endosperm starch is composed of $\approx 30 \%$ amylose and $70 \%$ amylopectin. Amylose synthesis is dependent on the waxy protein, granule bound starch synthase (GBSS). The waxy gene is coded on the $W x-B 1$ locus of chromosome 4A and group 7 homologous chromosomes of wheat and, thus, wild type (nonwaxy) wheat expresses three alleles of the waxy protein ( $W x A, W x B$, and $W x D$ alleles). Waxy starch is the result of mutations at the three $w x$ loci that encode the GBSS leading to a near complete reduction in amylose content. Hexaploid wheat requires mutation at all three loci (A, B, and D) to result in true waxy wheat. If only one or two loci are null, the wheat will be partially waxy with a reduced percentage of amylose compared with amylopectin content. Fully waxy wheats have very different starch pasting characteristics than nonwaxy wheats. For instance, Kiribuchi-Otobe et al (1997) and Hayakawa et al (1997) reported peak pasting viscosities of fully waxy wheats occurred $10-15^{\circ} \mathrm{C}$ lower than among nonwaxy (wild type) or partially waxy wheats.

Upon heating in excess water, starch imbibes water and swells and transforms from partially crystalline and amorphous granules to partially dissolved amorphous structures. Compared with wheat starch, maize (Zea mays L.) starch reportedly swells faster within the amorphous region of the granule because it contains more branched amylopectin chains that swell faster than amylose starch granules (Schoch 1965, Collison 1968, Tester and Morrison 1990).

\footnotetext{
${ }^{1}$ U.S. Department of Agriculture, Agricultural Research Service, Soft Wheat Quality Laboratory, 1680 Madison Ave., Wooster, OH 44691. Mention of a trademark or proprietary product does not constitute a guarantee or warranty of a product by the U.S. Department of Agriculture, and does not imply its approval to the exclusion of other products that also can be suitable.

${ }^{2}$ Corresponding author. E-mail: gaines.31@ osu.edu.

${ }^{3}$ University of Michigan, 8240 Medical Science, Pediatric Cardiology, Research Bld. III, 1550 West Medical Dr., Ann Arbor, MI 48109.

${ }^{4}$ U.S. Department of Agriculture, Agricultural Research Service, Grain Marketing and Production Research Laboratory, 1515 College Ave., Manhattan, KS 66502.

${ }^{5}$ Kansas State University, Dept. of Grain Science and Industry, Shellenberger Hall, Manhattan, KS 66506.
}

Publication no. C-2000-0211-02R.

This article is in the public domain and not copyrightable. It may be freely reprinted with customary crediting of the source. American Association of Cereal Chemists, Inc., 2000.
The small range in temperature when crystallinity is lost is the gelatinization temperature. With stirring and continued heating past the gelatinization temperature range, the swollen and partially dissolved granules reach a maximum (peak) viscosity. Fully or partially waxy starch takes less time to reach peak viscosity and swells more rapidly than wild-type starches.

Above a critical starch-water concentration, the gelatinized, swollen, ruptured, and partially dissolved and pasted starch will form a gel structure by coassociating during cooling. Both amylose and amylopectin interact during gelling. However, the more branched structure of amylopectin forms weaker associations and weaker gels.

Starch granule size distributions of hard and soft wheats mostly overlap. However, there are reports that cultivars of the hard market class tend to have more small starch granules or fewer large granules (depending on the analysis) than do cultivars of the soft market class (Glenn et al 1992, Bechtel et al 1993, Zayas et al 1994, Stoddard 1999). Recently, Raeker et al (1998) reported that starch granule size, amylose content, and starch phosphorus content significantly varied among 12 soft wheat cultivars. Smaller granules had more phosphorus content. Cultivars varied in their response to location and environment relative to those differences. Variation in amylose content suggested that flours from those wheats may vary in starch pasting and gel hardness characteristics. Data also suggested differences in starch granule particle size may be correlated with kernel texture, particularly because flour particle size is extensively used to define kernel texture. Starch granule particle size also could be correlated with other milling quality characteristics. The objectives of this study were to investigate those possibilities.

\section{MATERIALS AND METHODS}

Twelve soft wheat cultivars were evaluated as reported previously (Raeker et al 1998): Argee, Arthur, Augusta, Blackhawk, Caldwell, Fillmore, Freedom, Geneva, Hillsdale, McNair 1003, Pioneer 2550, and Pioneer 2555. Nonwheat material and shriveled kernels were removed from numerous nonbulked, cultivar-preserved samples. As described, three location composites were produced for each cultivar, except Blackhawk and Geneva, for which only two bulked samples were produced. Wheats were evaluated for kernel texture (softness equivalent) using a modified Brabender Quadrumat Jr. mill (Finney and Andrews 1986). 
Moisture and nitrogen contents were determined by AACC (1995) methods 44-15A and 46-12, respectively. Total starch content was determined using AACC (1995) method 76-13 using a total starch analysis kit by Megazyme (Megazyme Pty. Ltd., Warriewood, NSW, Australia).

Starch was isolated from each cultivar-location sample according to the method of McDonald and Stark (1988) with modifications as previously reported (Raeker et al 1998). To avoid the potential clumping of granules, another extraction procedure was used for particle size measurement. A modified protein digestion procedure was used to isolate the starch (Broklehurst and Evers 1977, Morrison and Scott 1986). Flour (0.3 g) was weighed and placed into Corex centrifuge tubes. Water $(5 \mathrm{~mL})$ and $2 \mathrm{~mL}$ of $0.8 \%(\mathrm{w} / \mathrm{v})$ pepsin A $(1: 60,000$ activity) in $0.04 \mathrm{~N} \mathrm{HCl}$ was added and incubated for $60 \mathrm{~min}$ at $37^{\circ} \mathrm{C}$. This treatment digested the majority of the gluten proteins present in the flour. Hemicellulase 90 (1 mL, 0.08\%, w/v) (Amano Enzyme U.S.A., Lombard, IL., $90,000 \mathrm{U} / \mathrm{g}$ activity) in $0.1 \mathrm{M}$ sodium acetate buffer, $\mathrm{pH} 4.5$, was added and incubated for $3 \mathrm{hr}$ at $45^{\circ} \mathrm{C}$. This enzyme removed the $\beta$-glucans that caused the starch to clump.

After incubation with this enzyme, $1 \mathrm{~mL}$ of a detergent mix $(5 \%$ w/v SDS, $5 \%$ v/v Teepol, 5\% v/v Triton X-100, 5\% v/v Tween 40, and 5\% v/v Triton X-15) was added. The isolated starch was centrifuged at $2,500 \times g$ for $5 \mathrm{~min}$, the supernatant was decanted, and the starch pellet was resuspended in $5 \mathrm{~mL}$ of water, vortexed, and centrifuged again. Water $(1 \mathrm{~mL})$ was added as a third wash, the starch slurry was transferred to a microcentrifuge tube, centrifuged for $1 \mathrm{~min}$, and the supernatant was removed. Sodium azide $1 \mathrm{~mL}$ of $1 \%(\mathrm{w} / \mathrm{v})$ was then used as the final wash to inhibit bacterial growth. The isolated starch was not further dried to avoid clumping of the granules.

Particle size characteristics of starches were determined by using a Malvern Mastersizer model X, equipped with Malvern application software version 1.1a (Malvern Instruments Inc., Southborough, MA). The instrument was equipped with a $45-\mathrm{mm}$ lens allowing a measured range in particle size of $0.1-80 \mu \mathrm{m}$ diameter, measured as spherical particles. Accuracy of the instrument was checked with standard glass particles (Duke Scientific Corp., Palo Alto, CA). The maximum particle size distribution of starch granules was usually $<60 \mu \mathrm{m}$.

For each cultivar-location treatment, $10 \mathrm{~mL}$ of deionized water containing $1 \%(\mathrm{v} / \mathrm{v})$ Triton $\mathrm{X}-100$ detergent was added to the starch suspension preparation. The instrument's small volume recirculating unit reservoir contained deionized water. Measurement used 2,000 sweeps. The polydispersed model was selected for calculation.
As described previously (Raeker et al 1998), total and apparent amylose contents of isolated starches were determined colorimetrically according to Morrison and Laignelet (1983). Apparent amylose content was measured before removal of starch lipids. Total amylose content was determined on the lipid-free starches that were prepared by precipitating starch from urea-dimethylsulfoxide solution with ethanol. Lipid-complexed amylose content was the difference between total and apparent amylose contents. Phosphorus content of the isolated wheat starch was determined according to procedure B in the method described by Morrison (1964). Phosphorus content in the starch sample was calculated from a standard curve prepared with phosphorus standard solutions (Sigma Chemical Co., St. Louis, MO). Total starch was based on wheat weight.

The hot pasting viscosity and time analysis of starch and flour was accomplished using a Rapid Visco Analyser (RVA), (model RVA-4, Foss North America, Eden Prairie, MN). The standard 1 heating profile of that instrument's software (Thermocline for Windows, version 2.0, Newport Scientific Pty. Ltd., Warriewood, NSW, Australia) was employed to produce pasting curves based on $3 \mathrm{~g}(14 \% \mathrm{mb})$ of starch or $4 \mathrm{~g}(14 \% \mathrm{mb})$ of flour and $25 \mathrm{~mL}$ of deionized water. Maximum heating temperature was $95^{\circ} \mathrm{C}$ and minimum cooled temperature was $50^{\circ} \mathrm{C}$. Peak pasting viscosity, peak time, minimum (trough) viscosity during cooling, breakdown viscosity (difference between peak and minimum viscosities), final viscosity at the conclusion of cooling, and setback (difference between final and minimum viscosities) were determined for each sample.

To evaluate the compressive hardness of starch gels, $3 \mathrm{~g}$ of starch was heated in $40 \mathrm{~mL}$ of deionized water $(7.5 \%)$ in the RVA to $95^{\circ} \mathrm{C}$. Gels were immediately poured into weighing pans that had snug-fitting lids. Pans were $6 \mathrm{~cm}$ in diameter and $2 \mathrm{~cm}$ tall. Starch slurries came to $\approx 12.5 \mathrm{~mm}$ up the sides of the pan. Lids were placed on the pans and samples were gelled during storage at $4^{\circ} \mathrm{C}$.

Preliminary observation showed that, being salt and buffer free, the gel hardness was asymptotic from $12 \mathrm{hr}$ to at least $36 \mathrm{hr}$. Starch gel hardness was evaluated after $24 \mathrm{hr}$ of storage. Gels were removed from storage and immediately were compressed in storage pans using a universal testing machine (model 1000) (Instron Corporation, Canton, MA) fitted with a 5-kg transducer and a 2-cm diameter round probe. Crosshead speed was $10 \mathrm{~mm} / \mathrm{min}$. Gel hardness was determined at $2 \mathrm{~mm}$ compression, which was before shear forces ruptured the gel.

Control samples from the cultivars Jagger and Chinese Spring (no null alleles, wild type [WT]), Chisolm (A null), Rio Blanco (B null), and Ike (A and B null) were extracted and analyzed in parallel with the experimental analyses. Starch was purified from flour

TABLE I

Mean Analytical and Milling Values for 12 Soft Wheat Starches ${ }^{a}$

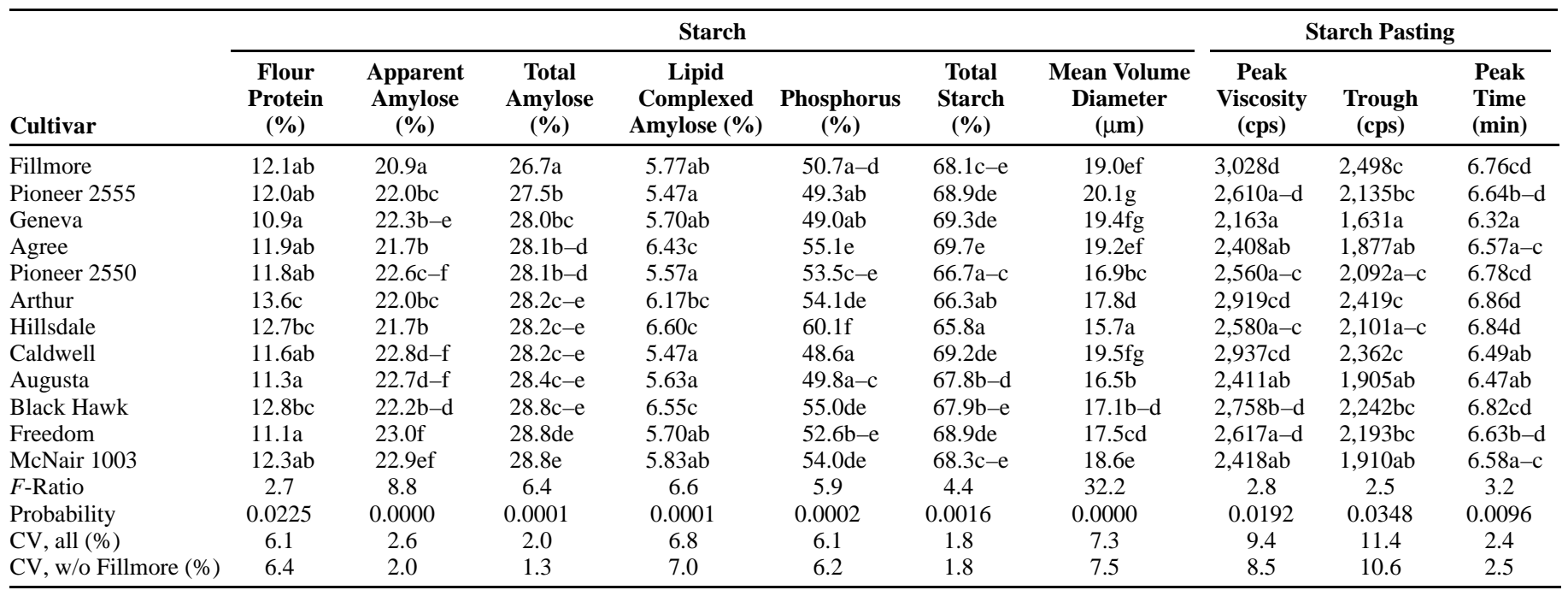

a Values followed by the same letter in the same column are not significantly different $(P<0.05)$. 
samples as described by Zhao and Sharp (1996) with the substitution of $30 \%(\mathrm{w} / \mathrm{v}) \mathrm{NaCl}$ for $80 \%(\mathrm{w} / \mathrm{v}) \mathrm{CsCl}$ (Echt and Schwartz 1981). Starch was suspended 1:30 (w/v) in sample buffer $(60 \mathrm{~m} M$ Tris, pH 8.8, $20 \mathrm{~m} M$ EDTA, 2\%, w/v, SDS, 10\%, v/v, glycerol) prepared with fresh DTT $(50 \mathrm{~m} M)$, boiled for $5 \mathrm{~min}$, placed on ice for $5 \mathrm{~min}$, and centrifuged $12,000 \times g$ for $10 \mathrm{~min}$. The liquid extract was removed from the gelatinized starch and alkylated with 4-vinylpyridine (Graybosch and Morris 1990).

Electrophoresis using the Mini Protean II system (BioRad) was performed with $20 \%(\mathrm{w} / \mathrm{v})$ acrylamide and $0.02 \%(\mathrm{w} / \mathrm{v})$ bisacrylamide (20\% $\mathrm{T}$ and $0.066 \% \mathrm{C}), 0.375 \mathrm{M}$ Tris, $\mathrm{pH}$ 7.8. Running gels were prepared from commercially available stock solution of $40 \%(\mathrm{w} / \mathrm{v})$ acrylamide and 2\% (w/v) bis-acrylamide (BioRad). The stacking gel was standard $(6 \%$, w/v) Laemmli composition. Both the running and stacking gels were prepared with the omission of SDS. The gels were held at $180 \mathrm{~V}$ (anode at the bottom of gel) until the dye front migrated off the bottom of the gel $(\approx 100$ $\mathrm{min}$ ) then for an additional $100 \mathrm{~min}$ at the same voltage. Gels were fixed and silver-stained (Blum et al 1987).

Polymorphism was determined by a band mobility change when visually comparing electrophoretic profiles of the wild type cultivars Jagger and Chinese Spring and the B null cultivar Rio Blanco. The band shift was denoted by a difference in electrophoretic mobility of the $W x-B 1$ protein that was observed to run between the $W x-D 1$ and $W x-B 1$ proteins of Jagger and Chinese Spring.

All measurements were replicated, and data were analyzed for analysis of variance using Statistica99 for Windows (StatSoft, Inc., Tulsa, OK). Differences among means of those analyses that were significant for cultivar effects were tested using least significant difference $(P<0.05)$. The analyses significant for cultivar were also examined for simple linear correlation. Significant $(P<$ $0.05)$ statistical correlations are reported with and without the Fillmore cultivar.

\section{RESULTS AND DISCUSSION}

Mean analytical values for the 12 starches, flours, and wheats that were significant $(P<0.05)$ for cultivar differences are ranked according to total amylose analysis and evaluated for cultivar differences in Tables I and II. Coefficients of variation among the cultivars, analysis of variance $F$-ratios for cultivar effect, and level of probabilities for the ratios are also shown. Correlation coefficients among those values are presented in Table III both for all cultivars and for all cultivars except Fillmore. The two sets of correlation coefficients were used to determine whether the dif- ferent amylose content of Fillmore affected the correlations by increasing the analytical ranges.

\section{Partial Waxy Starch Characteristics}

The method of Zhao and Sharp (1996) was modified to use a minigel format for the analysis of waxy alleles. Separation of GBSS proteins from the 12 soft wheat cultivars revealed three different patterns. A single null allele at the $W x-B 1$ locus was observed in the cultivar Fillmore, whereas the remaining 11 cultivars exhibited three functional waxy alleles. Polymorphism was detected among those 11 cultivars in the $W x-B 1$ locus in Argee, Blackhawk, Freedom, and McNair 1003. Polymorphism at the $W x-B 1$ allele was reported by Yamamori et al (1994) and RodriguezQuijano et al (1998), who found in a survey of 606 Iberian wheats that $58(9.5 \%)$ possessed polymorphism at the $W x-B 1$ allele.

The partial waxy mutation at the B locus of Fillmore coincides with the lower amylose content of this cultivar. Lack of the $W x-B 1$ protein results in a $3-4 \%$ decrease in amylose content measured as $\mathrm{mg}$ of amylose/100 mg of flour (Yamamori et al 1994, Zeng et al 1997, Graybosch et al 1998). The partial waxy cultivar Fillmore had $0.8-1.1$ percentage points less total amylose than the other cultivars. Waxy and partial waxy starches have a lower pasting temperature and a higher peak viscosity than nonwaxy starches (Hayakawa et al 1997, Kiribuchi-Otobe et al 1997, Zeng et al 1997). Partial waxy mutants lacking one or two GBSS alleles are similar to nonwaxy wheats in most characteristics with the exception of having lowered pasting temperatures, a distinguishing characteristic of waxy starch (Zeng et al 1997). Fillmore also demonstrated high starch peak viscosity, weak gel hardness, and short flour peak pasting time. Because Fillmore had high initial pasting viscosity, its concentration would be reduced and it would function as a good thickening agent in a soup or batter formulation at a lower concentration than nonpartially waxy wheats. However, its relatively weak cooled gel strength suggests that Fillmore may have relatively poor thickening performance.

\section{Flour Yield}

Brabender Quadrumat Jr. flour yield had the largest $F$-ratio for cultivar effect, indicating that flour yield had the lowest within cultivar variance component compared with error variance. Thus, flour yield had the highest genotypic control of all the quality tests conducted. Coefficients of variation were little affected by removing the partial waxy cultivar Fillmore. The correlation table shows that larger flour yields were produced from cultivars that had larger starch granules.

TABLE II

Mean Analytical and Milling Values for 12 Soft Wheat Flours ${ }^{\mathrm{a}}$

\begin{tabular}{|c|c|c|c|c|c|c|c|c|c|c|}
\hline \multirow[b]{2}{*}{ Cultivar } & \multirow[b]{2}{*}{$\begin{array}{c}\text { Starch Gel } \\
\text { Hardness } \\
\text { (units) }\end{array}$} & \multicolumn{3}{|c|}{ Milling } & \multicolumn{6}{|c|}{ Flour Pasting } \\
\hline & & $\begin{array}{c}\text { Softness } \\
\text { Equivalent } \\
(\%)\end{array}$ & $\begin{array}{l}\text { Flour } \\
\text { Yield } \\
(\%)\end{array}$ & $\begin{array}{c}\text { Flour Mean } \\
\text { Volume } \\
\text { Diameter }(\mu \mathbf{m})\end{array}$ & $\begin{array}{c}\text { Peak } \\
\text { Viscosity } \\
\text { (cps) }\end{array}$ & $\begin{array}{c}\text { Trough } \\
\text { (cps) }\end{array}$ & $\begin{array}{c}\text { Peak } \\
\text { Breakdown } \\
\text { (cps) }\end{array}$ & $\begin{array}{l}\text { Final Cooled } \\
\text { Viscosity } \\
\text { (cps) }\end{array}$ & $\begin{array}{l}\text { Setback } \\
\text { (cps) }\end{array}$ & $\begin{array}{l}\text { Time } \\
\text { (min) }\end{array}$ \\
\hline Pioneer 2555 & $12.2 b c$ & $59.8 \mathrm{de}$ & $74.5 \mathrm{hi}$ & $59.9 \mathrm{~b}$ & $5,113 d$ & $2,822 b-d$ & $2,292 \mathrm{de}$ & $5,226 \mathrm{c}-\mathrm{e}$ & $2,405 \mathrm{c}-\mathrm{e}$ & $6.00 \mathrm{a}-\mathrm{c}$ \\
\hline Geneva & $11.7 \mathrm{bc}$ & $59.4 c-e$ & $73.4 \mathrm{fg}$ & $62.7 b-d$ & $4,722 \mathrm{ab}$ & $2,556 \mathrm{ab}$ & $2,166 \mathrm{a}-\mathrm{d}$ & $5,194 \mathrm{~b}-\mathrm{e}$ & $2,639 \mathrm{f}$ & $5.90 \mathrm{ab}$ \\
\hline Agree & $11.9 b c$ & $59.3 \mathrm{c}-\mathrm{e}$ & $74.7 \mathrm{i}$ & $62.9 b-d$ & $4,791 \mathrm{a}-\mathrm{c}$ & $2,661 \mathrm{a}-\mathrm{c}$ & $2,129 a-c$ & $5,185 \mathrm{c}-\mathrm{e}$ & $2,524 \mathrm{ef}$ & $6.02 \mathrm{~b}-\mathrm{d}$ \\
\hline Caldwell & $12.8 \mathrm{c}$ & $61.7 \mathrm{e}$ & $72.8 \mathrm{ef}$ & $62.5 \mathrm{bc}$ & $5,142 \mathrm{~d}$ & $2,748 \mathrm{a}-\mathrm{d}$ & $2,393 \mathrm{e}$ & $5,264 \mathrm{c}-\mathrm{e}$ & $2,516 \mathrm{ef}$ & $6.00 \mathrm{a}-\mathrm{c}$ \\
\hline Augusta & $11.5 b c$ & $53.9 \mathrm{~b}$ & $71.8 \mathrm{c}$ & $77.8 \mathrm{fg}$ & $4,612 \mathrm{a}$ & $2,521 \mathrm{a}$ & $2,091 \mathrm{ab}$ & $4,938 \mathrm{~b}-\mathrm{d}$ & $2,417 \mathrm{de}$ & $6.00 \mathrm{a}-\mathrm{c}$ \\
\hline Black Hawk & $12.3 b c$ & $53.9 \mathrm{ab}$ & $73.8 \mathrm{gh}$ & $74.6 \mathrm{ef}$ & $4,638 \mathrm{a}$ & $2,472 \mathrm{a}$ & $2,166 a-d$ & $4,718 b$ & $2,246 b-d$ & $6.03 b-d$ \\
\hline Freedom & $12.7 \mathrm{c}$ & $56.9 b-d$ & $70.8 \mathrm{ab}$ & $70.4 \mathrm{de}$ & $4,746 \mathrm{ab}$ & $2,651 \mathrm{a}-\mathrm{c}$ & $2,095 \mathrm{ab}$ & $4,873 b c$ & $2,222 b c$ & $6.07 \mathrm{c}-\mathrm{e}$ \\
\hline McNair 1003 & $13.0 \mathrm{c}$ & $60.0 \mathrm{de}$ & $70.1 \mathrm{a}$ & $52.0 \mathrm{a}$ & $5,134 d$ & $2,867 \mathrm{~cd}$ & $2,267 \mathrm{c}-\mathrm{e}$ & $5,302 \mathrm{de}$ & $2,435 \mathrm{~d}-\mathrm{f}$ & $6.11 \mathrm{c}-\mathrm{e}$ \\
\hline$F$-Ratio & 3.0 & 8.2 & 41.7 & 15.1 & 4.4 & 3.0 & 9.9 & 5.2 & 11.5 & 4.8 \\
\hline
\end{tabular}

a Values followed by the same letter in the same column are not significantly different $(P<0.05)$. 
Higher flour yield was correlated with lower amylose content, lower starch phosphorus, and more total starch. Because flour yield is relatively highly genetically controlled (Schuler et al 1995, McKendry et al 1996), starch granule size, apparent amylose, total amylose content, starch phosphorus content, and total starch content also may be similarly controlled.

\section{Flour Pasting}

The $F$-ratios indicate that flour pasting parameters were as cultivar-dependent as were starch pasting parameters for most of the starch analytical tests. However, with the partial waxy cultivar Fillmore removed, the coefficient of variation of flour pasting peak breakdown and flour pasting setback were reduced, indicating that those parameters also may be partial waxy characteristics. Without Fillmore, the correlation coefficient between flour peak pasting viscosity and flour pasting final cooled viscosity were significantly different $(P=0.0004)$ from each other.

Removing Fillmore caused only three sets of measurements to have significantly different correlation coefficients $(P<0.05)$ : correlations between flour peak viscosity and flour peak breakdown, between flour peak viscosity and flour final cooled viscosity, and between flour pasting time and flour final cooled viscosity. Fillmore had the lowest flour final cooled viscosity $(P<0.05)$, lowest setback viscosity $(P<0.05)$, and lowest breakdown viscosity $(P<0.05)$.

Amylose content was correlated with flour pasting trough, breakdown, final cooled viscosity, setback, and pasting time when
Fillmore was included. Even though individual correlation coefficients were not particularly large, they produced a complete cycle for interpretation. For example, lower pasting viscosity was correlated with higher flour yield. Higher flour yield was correlated with lower amylose content. Lower amylose content was correlated with lower flour pasting time which was correlated with higher flour yield.

\section{Starch Pasting}

Only cultivar differences were significant for starch peak pasting viscosity, starch pasting trough, and starch pasting time. Removing Fillmore cultivar did not affect the coefficient of variability among cultivars. Starch peak pasting viscosity was correlated with flour peak pasting viscosity and starch peak pasting time was correlated with flour peak pasting time. Like flour pasting time, shorter starch pasting times were correlated with smaller starch granules and larger flour particle size (harder wheats). Higher starch pasting times were correlated with higher levels of lipid-complexed amylose content, higher phosphorus content, higher flour protein content, and lower levels of total starch content. In contrast to flour pasting characteristics, starch pasting characteristics were less well correlated with the various starch analyses. Neither flour nor starch pasting characteristics were correlated with milling yield or kernel texture.

Fully waxy wheats have $10-15^{\circ} \mathrm{C}$ lower starch peak pasting temperatures than nonwaxy (wild type) or partially waxy wheats

TABLE III

Correlation Coefficients Among Starch, Starch Pasting, Starch Gel, Milling Parameters, and Flour Pasting Analyses

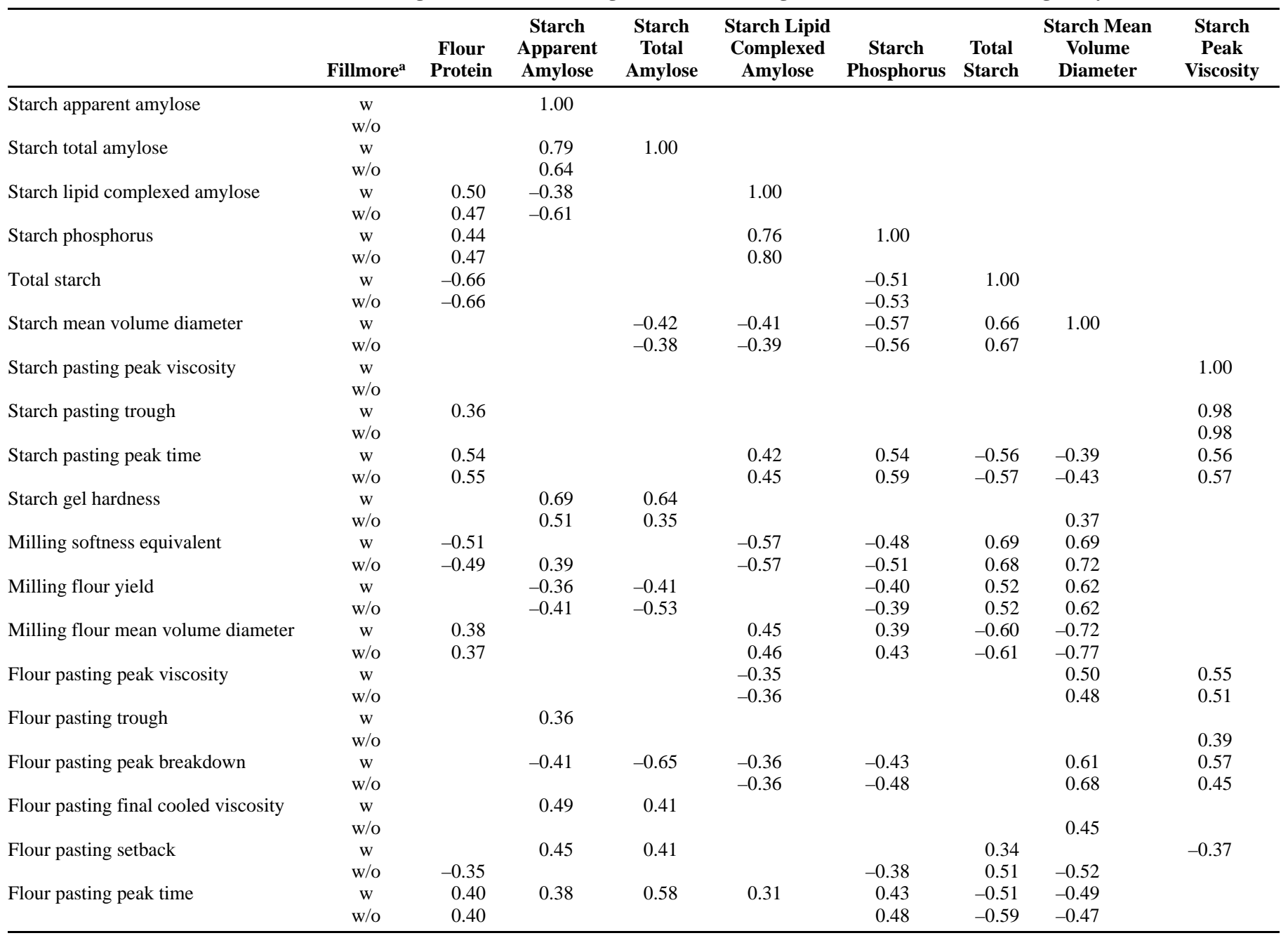

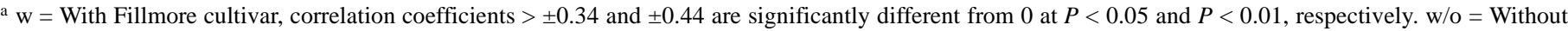
Fillmore cultivar, correlation coefficients $> \pm 0.35$ and \pm 0.45 are significantly different from 0 at $P<0.05$ and $P<0.01$, respectively. 
(Hayakawa et al 1997, Kiribuchi-Otobe et al 1997), indicating that they paste at shorter times. Kiribuchi-Otobe et al (1997) reported that fully waxy wheats reached peak pasting temperature $\approx 50 \%$ faster than nonwaxy wheats. The present wheats exhibited a $50 \mathrm{sec}(12 \%)$ range in pasting time. Starches that had shorter pasting times also had lower levels of lipid-complexed amylose content, less phosphorus content, lower flour protein content, smaller starch granule mean volume diameter, softer kernel texture, and higher levels of total starch content.

\section{Gel Hardness}

Higher gel strength is sometimes desirable in coatings and binders to produce greater structure and a crisp bite. Large deformation rheological compression measurements were used to evaluate starch gel hardness in pure starch-water concentrations without added buffers or salt, which may preferentially inhibit the reordering of the amylopectin fraction of starch gels during aging (Russell and Oliver 1989). The coefficient of variation of starch gel hardness among the cultivars was increased by the presence of the lower amylose partial waxy cultivar Fillmore. Higher amylose values were correlated with greater gel hardness. Harder gels were produced from softer wheats (higher softness equivalent and smaller flour mean volume diameter values).

Starch pasting characteristics were not significantly correlated with gel hardness. However, with the partial waxy cultivar Fillmore included in the data set, harder gels generally were produced from flours that had higher values for flour pasting trough, breakdown, final cooled viscosity, set back, and peak time. Being lower in amylose, Fillmore had relatively high pasting viscosity but produced relatively weak gels.

\section{Kernel Texture}

Softer kernel texture is defined by larger values for milling softness equivalent and by smaller values for flour mean volume diameter. Mean volume diameter, particularly, had a relatively large $F$-ratio for significance among cultivars and the coefficients of variation were not reduced by removing the partial waxy cultivar Fillmore. Those observations indicate that, among these soft wheat cultivars, kernel texture was more genetically controlled.

Softer textured wheats (larger softness equivalent values and smaller flour mean volume diameter values) were correlated with larger starch granules (larger mean volume diameter values). Similar observations have been reported comparing wheats across the hard and soft market classes (Glenn et al 1992, Bechtel et al 1993, Zayas et al 1994) but not within the soft red winter wheat market class. Thus, it appears that some soft wheats are softer that others, in part because they have larger starch granules that construct a more loosely compacted and softer endosperm structure. They also have less surface area for bonding with other endosperm components.

Kulp observed (1973) that smaller starch granules had higher ranges of gelatinization temperature. Zeng et al (1997) observed

TABLE III (continued)

Correlation Coefficients Among Starch, Starch Pasting, Starch Gel, Milling Parameters, and Flour Pasting Analyses

\begin{tabular}{|c|c|c|c|c|c|c|c|c|c|c|}
\hline $\begin{array}{l}\text { Starch } \\
\text { Pasting } \\
\text { Trough }\end{array}$ & $\begin{array}{c}\text { Starch } \\
\text { Pasting } \\
\text { Peak Time }\end{array}$ & $\begin{array}{c}\text { Starch Gel } \\
\text { Hardness }\end{array}$ & $\begin{array}{c}\text { Milling } \\
\text { Softness } \\
\text { Equivalent }\end{array}$ & $\begin{array}{c}\text { Milling } \\
\text { Flour Yield }\end{array}$ & $\begin{array}{c}\text { Milling Flour } \\
\text { Mean Volume } \\
\text { Diameter }\end{array}$ & $\begin{array}{c}\text { Flour } \\
\text { Pasting Peak } \\
\text { Viscosity }\end{array}$ & $\begin{array}{c}\text { Flour } \\
\text { Pasting } \\
\text { Trough }\end{array}$ & $\begin{array}{c}\text { Flour } \\
\text { Pasting Peak } \\
\text { Breakdown }\end{array}$ & $\begin{array}{c}\text { Flour Pasting } \\
\text { Final Cooled } \\
\text { Viscosity }\end{array}$ & $\begin{array}{c}\text { Flour } \\
\text { Pasting } \\
\text { Setback }\end{array}$ \\
\hline
\end{tabular}

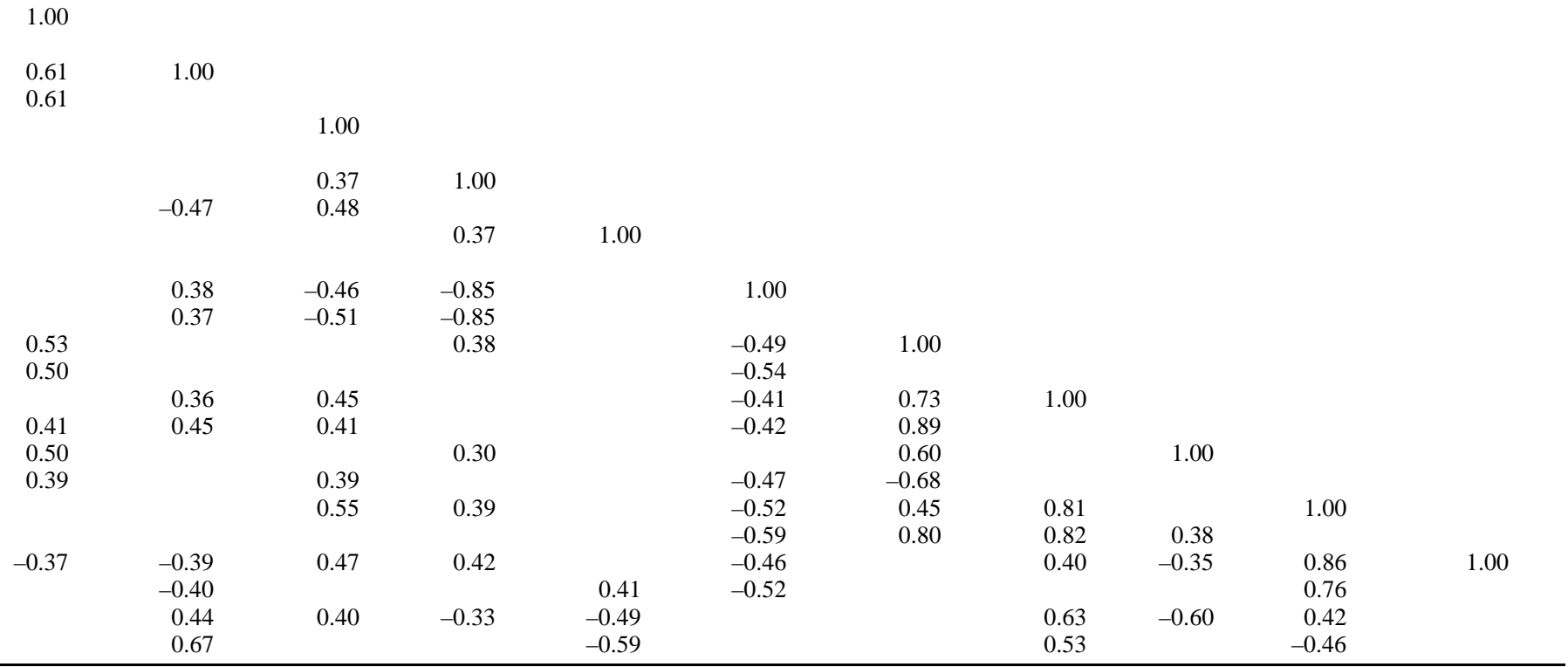


that harder soft wheats had higher temperatures for the onset of gelatinization. Peng et al (1999) found that small B-type granules had $1-2^{\circ} \mathrm{C}$ higher peak and completion DSC gelatinization temperatures. Therefore, the present study suggests that the higher gelatinization times and temperatures of the harder textured soft wheats evaluated by Zeng et al (1997) were caused by the smaller starch granule size of those harder wheats.

\section{CONCLUSIONS}

Zeng et at (1997) reported that three partially waxy wheats each from different market classes (soft white winter, soft white spring, and a soft red spring) had relatively high peak pasting viscosities and lower cooled paste viscosities. In the present study, the soft red winter wheat Fillmore was identified as having partially waxy starch with appropriate pasting characteristics, including high peak pasting viscosity and earlier flour peak pasting time. Fillmore also produced weaker starch gel strength than the nonwaxy starches of the other cultivars evaluated.

Milling flour yield and starch particle size were strongly genetically controlled. Being correlated with either of those parameters, other starch characteristics (amylose content, lipid complexed amylose, and phosphorus content) also appear to be genetically controlled. Milling yield was greatest from the wheats with larger starch granules that have smaller surface area and less opportunity for interconstituent bonding.

Flour particle size and starch granule size were inversely correlated. The observation that the soft wheat cultivars that had harder textured kernels also had smaller starch granules, suggests that those cultivars are harder because the granules within the endosperm cells have more surface area for noncovalent bonding and may be more tightly and firmly compacted.

These findings demonstrate that the soft wheat breeder, miller, and baker could exploit to their benefit natural variation in starch qualities found among soft wheat cultivars, particularly as they affect kernel texture and flour yield. Characterization of starch qualities and their effect on end use qualities should receive additional investigation.

\section{ACKNOWLEDGMENTS}

This research was partially supported by USDA-NRI Grant 96-355003323 Project G9986 to Paul A. Seib and George L. Lookhart.

\section{LITERATURE CITED}

American Association of Cereal Chemists. 1995. Approved Methods of the AACC, 9th ed. Method 44-15A, final approval October 1975, revised October 1994; Method 46-12, final approval October 1976, reviewed October 1994; Method 50-11, final approval November 1989, reviewed October 1994, Method 76-13, first approval November 1995. The Association: St. Paul, MN.

Bechtel, D. B., Zayas, I., Dempster, R., and Wilson, J. D. 1993. Sizedistribution of starch granules isolated from hard red winter and soft red winter wheats. Cereal Chem. 70:238-240.

Blum, H., Beier, H., and Gross, J. H. 1987. Improved silver staining procedure for plant proteins, RNA and DNA in polyacrylamide gels. Electrophoresis 8:93-99.

Brocklehurst, P. A., and Evers, A. D. 1977. The size distribution of starch granules in endosperm of different sized kernels of the wheat cultivar Maris Huntsman. J. Sci. Food Agric. 28:1084-1089.

Collison, R. 1968. Swelling and gelation of starch. Page 168 in: Starch and Its Derivatives. J. A. Radley, ed. Chapman and Hall: London.
Echt, C. S., and Schwartz, D. 1981. Evidence for the inclusion of controlling elements within the structural gene at the waxy locus in maize. Genetics 99:275-284.

Finney, P. L., and Andrews, L. C. 1986. A 30-minute conditioning method for micro-, intermediate-, and large-scale experimental milling of soft red winter wheat. Cereal Chem. 63:18-21.

Glenn, G. M., Pitts, M. J., Liao, K., and Irving, D. W. 1992. Blocksurface staining for differentiation of starch and cell walls in wheat endosperm. Biotechnol. Histochem. 67:88-97.

Graybosch, R. A., and Morris, R. 1990. An improved SDS-PAGE method for the analysis of wheat endosperm storage proteins. J. Cereal Sci. 11:201-212.

Graybosch, R. A., Peterson, C. J., Hansen, L. E., Rahman, S., Hill, A., and Skerritt, J. H. 1998. Identification and characterization of U.S. wheats carrying null alleles at the $w x$ loci. Cereal Chem. 75:162-165.

Hayakawa, K., Tanaka, K., Nakamura, T., Endo, S., and Hoshino, T. 1997. Quality characteristics of waxy hexaploid wheat (Triticum aestivum L.) Properties of starch gelatinization and retrogradation. Cereal Chem. 74:576-580.

Kiribuchi-Otobe, C., Nagamine, T., Yangisawa, T., Ohnishi, M., and Yamaguchi, I. 1997. Production of hexaploid wheats with waxy endosperm character. Cereal Chem. 74:72-74.

Kulp, K. 1973. Characteristics of small-granule starch of flour and wheat. Cereal Chem. 50:666-679.

McDonald, A. M., and Stark, J. R. 1988. A critical examination of procedures for the isolation of barley starch. J. Inst. Brew. 94:125-132.

McKendry, A. L., Tague, D. N., Finney, P. L., and Miskin, K. E. 1996. Effect of 1BL.1RS on milling and baking quality of soft red winter wheat. Crop Sci. 36:848-851.

Morrison, W. R., and Laignelet, B. 1983. An improved colorimetric procedure for determining apparent and total amylose in cereal and other starches. J. Cereal Sci. 1:9-20.

Morrison, W. R., and Scott, D. C. 1986. Measurement of the dimensions of wheat starch granule populations using a Coulter Counter with 100channel analyzer. J. Cereal Sci. 4:13-21.

Peng, M., Gao, M., Abdel-Aal, E.-S. M., Hucl, P., and Chibbar, R. N. 1999. Separation and characterization of A- and B-type starch granules. Cereal Chem. 76:375-379.

Raeker, M. Ö., Gaines, C. S., Finney, P. L., and Donelson, T. 1998. Granule size distribution and chemical composition of starches from 12 soft wheat cultivars. Cereal Chem. 75:721-728.

Rodriguez-Quijano, M., Nieto-Taladriz, M. T., and Carrillo, J. M. 1998. Polymorphism of waxy proteins in Iberian hexaploid wheats. Plant Breed. 117:341-344.

Russell, P. L., and Oliver, G. 1989. The effect of $\mathrm{pH}$ and $\mathrm{NaCl}$ content on starch gel ageing. A study by differential scanning calorimetry and rheology. J. Cereal Sci. 10:123-138.

Schoch, T. J. 1965. Starch in bakery products. Baker's Dig. 39(2):48-52, 54-57.

Schuler, S. F., Bacon, R., Finney, P. L., and Gbur, E. 1995. Relationship of test weight and kernel properties to milling and baking quality in soft red winter wheat. Crop Sci. 35:949-953.

Stoddard, F. L. 1999. Survey of starch particle-size distribution in wheat and related species. Cereal Chem. 76:145-149.

Tester, R. F., and Morrison, W. R. 1990. Swelling and gelatinization of cereal starches. I. Effects of amylopectin, amylose, and lipids. Cereal Chem. 67:551-557.

Yamamori, M., Nakamura, T., Endo, T. R., and Nagamine, T. 1994. Waxy protein deficiency and chromosomal location of coding genes in common wheat. Theor. Appl. Genet. 89:179-184.

Zayas, I. Y., Bechtel, D. B., Wilson, J. D., and Dempster, R. E. 1994. Distinguishing selected hard and soft red winter wheats by image analysis of starch granules. Cereal Chem. 71:82-86.

Zeng, M., Morris, C. F., Batey, I. L, and Wrigley, C. W. 1997. Sources of variation for starch gelatinization, pasting, and gelation properties in wheat. Cereal Chem. 74:63-71.

Zhao, X. C., and Sharp, P. J. 1996. An improved 1D SDS-PAGE method for identification of three bread wheat 'waxy' proteins. J. Cereal Sci. 23:191-193.

[Received July 12, 1999. Accepted November 30, 1999.] 